\title{
The Effects of High Median Age on Currency of Resources in Community College Library Collections
}

\section{Anna H. Perrault, Richard Madaus, Ann Armbrister, Jeannie Dixon, and Rhonda Smith}

In 1998, a comprehensive study was conducted of the monograph collections of the twenty-eight public community colleges in Florida. This article reports the findings of that study with respect to median age and currency of resources. The rationale for the interpretation of the findings in the Florida Community College Collection Assessment Project is congruent with the philosophy that college collections should emphasize the instructional and curricular needs of students and, therefore, that the collections should emphasize current resources rather than retrospective depth. The findings on median age from the Florida Community College study serve as an example for the discussion of the implications of median age on currency of resources in college library monographic collections, especially in the professional, scientific, and technical fields. The major recommendation is a Continual Update Collection Management Model for college collections.

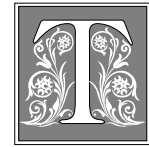

raditionally, median age and currency of collections have not been concerns in the research library arena because, by definition, research libraries seek to build collections with retrospective depth. Under this collection-building philosophy, the humanities and historically oriented disciplines were the prominent collecting areas in academic libraries. Traditional principles of collection development began to undergo change in the 1980s when the effects of the escalation in serials pricing on monograph purchasing were beginning to be apparent. The ARL statistics series revealed a decline in purchasing power and in actual number of materials purchased in the latter 1980s. ${ }^{1}$ The catchphrase for academic libraries caught in the acquisitions budget crisis became "Just in time, not just in case."

The just-in-time philosophy would seem to favor fields in which current information is paramount. Indeed, research revealed that in ARL libraries, the science/technology

Anna H. Perrault is Associate Professor in the School of Library and Information Science at the University of South Florida; e-mail: perrault@luna.cas.usf.edu. Richard Madaus is Director of the College Center for Library Automation; e-mail: madausr@lincc.ccla.lib.fl.us. Ann Armbrister is Associate Director of the College Center for Library Automation; e-mail: armbria@lincc.ccla.lib.fl.us. Jeannie Dixon is Assistant Director of Library Software Operations at the College Center for Library Automation; e-mail: jeannie@lincc.ccla.lib.fl.us. Rhonda Smith is Reference Librarian at the Florida Distance Learning Reference and Referral Center; e-mail: rhonda@dudley.lib.usf.edu. 
fields had gained in percentage share of monographic acquisitions compared to the humanities/arts and social sciences. ${ }^{2}$ Yet, little attention has been given to currency and obsolescence in monograph collections with respect to the effects of high median ages, particularly in science/technology materials and increasingly technologically focused curricula.

This article reports the findings of a study of community college collections in Florida with respect to median age and currency of monographic collections. The interpretation of the findings generalizes the effects of median age on currency of collections to the universe of college libraries.

\section{The Florida Community College Collection Assessment Study}

Florida is unique in that the public community colleges share one statewide network, the Library Information Network for Community Colleges (LINCC), which is provided through the College Center for Library Automation (CCLA). From the LINCC aggregated database, standardized data for all twenty-eight Florida community college library/learning resource center collections can be obtained. A comprehensive study of the monograph collections of Florida community colleges was conducted by CCLA in 1998 through data extracted from the LINCC database. This comprehensive study was preceded by an earlier study which was reported at Library Research Seminar I, "Partners and Paradigms," held in Tallahassee, Florida, November 1-2, 1996. ${ }^{3}$

\section{In the past few years, most current information, reference and indexing services, and selected journal literature have been converted to electronic formats.}

The major finding of the 1996 study of the aggregated resources base of the Florida community college collections by imprint year was that the monographic resources of Florida community colleges are significantly out of date. In addition, it was found that in the 1990s, the num- ber of older materials had increased in percentage share to that of current materials. The analysis by subject divisions revealed that outdated materials are prevalent in all major subject divisions, including the sciences and technology in which currency of materials is imperative. ${ }^{4}$ The profile by age obtained for the aggregated resources base and three individual library/learning resources centers in 1996 suggested that more in-depth quantitative analysis was needed.

The findings of the 1996 collection assessment study were incorporated into a Program Review of the community college library/learning resource centers (L/ LRCs) in Florida commissioned by the Florida Division of Community Colleges. ${ }^{5}$ One consequence of the LINCC Collection Assessment and the Program Review was the preparation of a budget request for remedial funding to address the inadequacy of resources in the community college L/LRCs. The Learning Resources Standing Committee of the Division of Community Colleges also recommended that a comprehensive study be conducted of the collections of all twenty-eight Florida community colleges. The comprehensive study of Florida community college collections and the full report of the collection assessment project were completed in September 1998. ${ }^{6}$

\section{The Problem}

As a background to the problem of median age in college collections, it is necessary to differentiate the collection development philosophy for community colleges and primarily undergraduate four-year academic libraries from that of research libraries. The most recent statement of collection development philosophy for community college collections is in Wanda $\mathrm{K}$. Johnston's Administering the Community College Learning Resources Program. ${ }^{7}$

Community college collection development is directly related to the college mission. It requires an understanding of the informational and instructional needs of its students, 
faculty, administrators, and broader college community. The primary purpose of the college's collection development is to support the instructional program. Consequently, appropriate resources are selected to serve diverse student learning styles and abilities; to support transfer, vocational, developmental, and community interest courses; and to use alternative information delivery systems. Faculty research and esoteric requests usually are fulfilled through external sources via resource sharing agreements. Thus, participation in broader cooperative networks is necessary to expand the instructional resources available on campus and to support research needs. ${ }^{8}$

This statement is in the same vein as earlier statements on the mission of college libraries. At a conference in 1975, Evan Farber provided a description of the purpose of college libraries:

... a college library is very different from a university library, not just in size but also in purpose. Moreover, the needs of college undergraduates have to be determined by different criteria than those used for university students. A college library must have, first of all, a collection of cultural and recreational materials that can expand students' horizons; second, a good basic collection that will meet most of their curricular needs; and third, a good reference collection that will serve as a key to the immediate library, and to resources elsewhere. Only after these three needs are met should we think about a collection to fill the occasional research need. We should aim for a well-chosen basic collection that meets the first two needs, plus enough advanced materials to meet most of the students' research needs, and then depend on outside sources for the remainder ... College librarians should be thinking of "reference-centered" libraries, not "book-centered" (that is warehouse-type) libraries. ${ }^{9}$

Both these statements emphasize the development of collections that support the instructional program and fit the curricular needs of the students. Although neither statement directly emphasizes the need for current materials, it is implied in that both statements stress instructional and reference services. In the past few years, most current information, reference and indexing services, and selected journal literature have been converted to electronic formats. Many states, including Florida, have electronic resources packages provided through statewide consortial arrangements. Although the availability of electronic resources meets a portion of the current information needs of students, the development and maintenance of monograph collections remains an important aspect of the mix of resources being provided by the college library.

The problem is twofold: the analysis of the collections to study the distribution of monographs by subject and age (publication date), and the interpretation of the findings with respect to median age and its effects on the currency of collections. Do the monograph collections of the community colleges contain materials in sufficient numbers and level of currency to provide adequate resources and services for the students of those institutions?

\section{Research Design}

The research design for the study is a collection analysis of the Florida community college collections, both individually and collectively, as an aggregated resources base. The twenty-eight public community colleges in Florida share a statewide database, LINCC, which reflects the aggregated resources of community college L/ LRC collections in Florida. Data extraction from the LINCC database for the monographic collection assessment took place in May-June 1998. Only bibliographic records with a monographic tag were extracted. Five broad subject groupings and forty-seven individual disci- 
plines and fields were defined for the study.

The study analyzed monographic records divided into five-year periods beginning with 1970. All imprints prior to 1970 formed a grouping of pre-1970 titles. Analysis and interpretation of the data are by the aggregated database, LINCC, and each of the twenty-eight community college L/LRCs individually. The analysis of the study findings in the Florida Community College Assessment Report concentrates on the distribution of publications by subject and age (publication date).

\section{The Florida community colleges can be regarded as representative of the majority of the community colleges in the United States.}

This study is unique in that it is the first statewide study of community colleges utilizing data extracted from a cooperative database. Hence, the data are comparable for each of the twenty-eight community colleges. The distribution of collections by age is not a measure often calculated for any size and type of library collection. The data necessary to calculate median age have not been routinely gathered. Median age requires that the distribution of titles by subject and imprint year be known. Few online catalog databases include this type of data report as a standard feature. Indeed, it is a difficult data set to obtain due to the programming involved, even when the vendor or database management is cooperative. There are no reported data from like studies with which to compare the findings, especially with regard to median age

The Florida community colleges can be regarded as representative of the majority of the community colleges in the United States. The funding trends in higher education for the past fifty years, on average, have been similar for institutions of higher education. The trends in collecting found in the LINCC study can be assumed to be typical patterns for many college libraries. To set the findings of the Florida Community College Collection Assessment into the broader arena of academic library collections, it is necessary to review the literature for research germane to the context of the study.

\section{Review of the Research}

One approach to the problem of judging the appropriateness of median ages is to look at the rate at which materials become obsolescent by disciplines or fields of study. This review of research first summarizes previous reviews on obsolescence and weeding. Then the findings of those individual studies germane to the interpretation of the findings of the Florida Community College Collection Assessment Study are reviewed.

\section{Reviews on Obsolescence and Weeding}

The most active period of research in obsolescence was the 1960s and 1970s. It is not within the scope of this review to cover again all the studies in this body of literature, which has been the subject of several thorough review articles. The most comprehensive review of the literature of obsolescence was published by Maurice B. Line and Alexander Sandison in 1974. ${ }^{10}$ This is the definitive review of the research in obsolescence, being both analytical and critical. Line and Sandison define the concept of obsolescence as "the decline over time in validity or utility of information." ${ }^{\prime 11}$

Their review includes an appendix of "Studies giving date or age data for library uses or references citations." ${ }^{12}$ A total of 170 studies are reviewed and listed in the appendix, which is in tabular format and divided into sections according to type of study:

- Use studies: Individual libraries

- Use studies: Interlibrary loans

- Reference/citation studies: -Synchronous (one source period) -Two or more source periods -Diachronous -Relative

- Analyses of references

For each study, the type of library, form of material, year of data collection, number of items studied, and intervals of data distribution are given. This listing of the various studies with brief descriptions of the type of data collected forms an inven- 
tory of the research up to that point in time. Line and Sandison summarized the characteristics of the studies:

In the first place, most of them are concerned with science and technology (with medicine having more than its share); there are a few in social science, a few library studies spanning several subjects, and almost none devoted to the humanities. Secondly, they nearly all deal with research literature or academic libraries. Thirdly, many are based on very small samples, and few are comparable with one another, because of the differences in, for example, age grouping. Fourthly, many, especially the synchronous studies, rely on agebiased data so that their conclusions are misleading or invalid. ${ }^{13}$

It is interesting to note that the studies divide into two main types: use studies, and references or citation studies. Many of the use studies are performed on the monographic literature because books circulate. The studies of references or citations are almost all studies of the journal literature. Very few studies have been conducted that either deal with median age in monograph collections or study obsolescence of monographs according to discipline. The section of the review article by Line and Sandison on "Use of Monographs" includes the findings of only four studies. Those germane to the research reported in this paper are reviewed in the section on individual studies later in this review.

From their analysis of the research on obsolescence, Line and Sandison suggest hypotheses for examination:

Literature may decline in use faster when

(a) it deals with data of ephemeral relevance

(b) it is in the form of a 'report', thesis, 'advance communication' or pre-print

(c) it is in a rapidly advancing technology

Literature may decline in use more slowly when (a) it is descriptive

(b) it deals with concepts

(c) it is critical ${ }^{14}$

These hypotheses are useful to formulate broad guidelines by category or type of material rather than obsolescence rates by discipline. In their conclusion, Line and Sandison comment that any summary of the present state of knowledge in the obsolescence of materials "would be misleading." They state as hypotheses what some have stated previously as fact. They list twelve recommendations for further research. ${ }^{15}$ Line and Sandison simply conclude that the research findings in obsolescence of library materials are insufficient to formulate obsolescence rates. They contend that the point of obsolescence studies should be to project the future use of materials because that is what librarians really need to know.

In 1981, D. Kaye Gapen and Sigrid P. Milner updated the previous reviews of the research on obsolescence. ${ }^{16}$ Few studies had been published since the review by Line and Sandison. Gapen and Milner conclude that:

Much basic research remains to be done on obsolescence. Researchers have taken the concept as proven, but in fact it still only a [sic] hypothesis. The studies that have been done have concentrated heavily on scientific fields at the expense of the social sciences and the humanities, and journal articles at the expense of monographs. More should be done in the humanities, if only to determine whether obsolescence is a concept which cannot be usefully applied outside the sciences. ${ }^{17}$

Gapen and Milner observe that many studies have been "motivated by the need to withdraw something and have been interested only in what should be discarded, not in an ideally objective model."18 They are critical of the findings of most of the research in obsolescence: "Ideally for remote storage or discarding, research on obsolescence has produced many mathemati- 
cal formulas, but unfortunately they have been neither simple nor universally applicable." They term only that research that has been "transmogrified into bibliofolklore," such as journals can be discarded after seven years, as simple, but "much of it is generally incorrect."19 The authors propose a "problem-solving management model," which they describe in general terms but do not actually develop. ${ }^{20}$

Line updated the previous review of obsolescence studies in 1993. ${ }^{21}$ A considerable number of studies had been performed since the 1974 review, most of which were citation studies of journals or journal articles. Line's summary of the literature is very similar to that of the 1974 review: "there has been a good deal more discussion of the matter, and additional light has been shed on the theory, but much research remains to be done, unwarranted statements continue to be made, and there has been little contribution to the practical applications of literature use decay." 22 Of relevance to the research reported in this article is the observation that because "articles are intended to report research at the frontiers and therefore date more rapidly than books, which consolidate knowledge," "citations to journals show a faster decay rate than citations to books." ${ }^{23}$ Line concludes by observing that the "virtual library" may ease the space pressure on libraries, but that if books and articles are to be accessed remotely, there "will have to be immense improvements in indexing." He proposes that it is technically possible to make the title pages, contents, pages, and even indexes to books available online. ${ }^{24}$

A theoretical article by Dianne Rothenberg appears in the same issue of Library Trends in 1993 as the updated review by Line. ${ }^{25}$ Rothenberg suggests that parameters of obsolescence-characteristics of the knowledge base, characteristics of publications studied, characteristics of uses, characteristics of users, characteristics of the setting, and time spanare all "co-occurring events that affect changing uses of print materials over time." ${ }^{26}$ Rothenberg poses several research questions for further study and observes that "studies of changing uses of print materials over time need more sophisticated analysis than conclusions reached through frequency counts." 27

The literature of obsolescence cannot be separated entirely from the literature of weeding because much of the research in obsolescence has been conducted for the purpose of developing criteria for weeding. Likewise, much of the research in obsolescence is concerned with use of materials because the literature of weeding and obsolescence center on the factor of use. Indeed, many of the same studies are reviewed, whether the focus of the review is obsolescence or weeding.

The literature of weeding has been thoroughly reviewed by Stanley J. Slote, who published the first edition of Weeding Library Collections in 1975 with the most recent edition in $1997 .{ }^{28}$ The bulk of the literature on weeding is concerned with procedures for weeding based on determining past and future potential use of materials.

The classic studies in weeding were conducted in the 1960s and 1970s. These studies sought to take advantage of the computational powers of computers to conduct research on the use of library materials. The theoretical studies by Winston C. Lister, ${ }^{29}$ Aridaman K. Jain, ${ }^{30}$ Herman H. Fussler and Julian L. Simon, ${ }^{31}$ Michael K. Buckland, ${ }^{32}$ Richard W. Trueswell, ${ }^{33}$ Allen Kent et al, ${ }^{34}$ and Slote ${ }^{35}$ all sought to develop mathematical formulae or objective criteria for the selection of materials for storage or weeding. Trueswell's research became the most prominent of the weeding studies with his theory of weeding by "last circulation date." 36 Using the findings of earlier research, he sought to identify a core collection by assuming that a small proportion of the collection satisfies a large proportion of the circulation. He examined circulation records to determine the age of the materials circulating and the number of times these materials had previously circulated. In addition, he defined core collection as "a percentage of the collection that should satisfy a given level of the user cir- 
culation requirements" rather than a set of specific subject materials. ${ }^{37}$ The converse of this was to attempt to define what percentage of user needs is not satisfied by the core collection. From the circulation studies he had conducted, Trueswell then set out to develop a weeding procedure based on the core collection principle. This was the "last circulation date" theory. He emphatically stated that all books should be removed that had "not circulated during the previous eight year period." ${ }^{\prime 38}$ Trueswell had developed a quantitative approach that predicted the size of the core collection and that helped identity candidates for weeding and the desired effect of the weeding on circulation. His proposal of weeding by "last circulation date" received much attention and was incorporated into methods for weeding library collections by Slote and others.

From this review of the literature on obsolescence and weeding, only a few studies were found that are directly germane to the consideration of age of materials, or median age, or obsolescence of monographs by field or discipline. Those studies are reviewed in the next section.

\section{Individual Studies}

The landmark study of the effects of age on use of monographic literature was that of Fussler and Simon, which has been cited in every literature review for obsolescence and weeding. Fussler and Simon investigated the patterns of book use in several universities. Looking at book use by publication period, they found that the "more a book was used at first, the faster it was likely to decline in use," that "past use was the best predictor of future use," and that decline with time "differed substantially between subjects." 39

Fussler and Simon tested objective criteria they developed for weeding against the expert opinion of faculty in a number of disciplines, including chemistry, economics, and literature in English and Teutonic languages. There was almost total agreement between the objective criteria and the experts in the "cumulative disciplines" of chemistry and economics, but not in the humanities. This was seen as an indication that "a differential plan might well be the best policy" for weeding. ${ }^{40}$

One of the earliest studies of obsolescence in monographic literature is by Charles F. Gosnell. His article "Obsolescence of Books in College Libraries" was first published in 1944 and reprinted in Collection Management in 1978. ${ }^{41}$ Using three book lists of recommended college library acquisitions, Gosnell found that different subjects in the lists had varying obsolescence rates of from 1.5 to 31.3 years, with the overall averages in the 8.1to 9.6-year range. His interpretation of "obsolescence rate" was that the lower the rate, the higher the number of older materials in that subject area. Materials that become obsolescent quickly have a higher obsolescence rate. A low number, such as four or five, means the material obsolesces more quickly, in four to five years. Conversely, a higher number, such as twentyone, means the material has a long period of usefulness. After analyzing three standard selection lists, Gosnell then studied the collections of five college libraries and previous circulation studies in college libraries. He found the libraries had lower obsolescence rates, that is, a higher proportion of older materials than the selection lists. ${ }^{42}$

Gosnell emphasized the validity of the formula he developed for calculating obsolescence rates rather than findings of obsolescence rates by certain subject disciplines. Indeed, in the table "Rates of Obsolescence in College Libraries," there are only four subject categories listed with obsolescence rates for each of the five college libraries in the study. The rates vary considerably for the same subjects from one college to another. ${ }^{43}$ The highest overall obsolescence rate in libraries was 4.9 years. There are actually little data on obsolescence rates of literature by discipline in the Gosnell study.

From his findings, Gosnell considers an average obsolescence rate for a college library to be five percent a year. Assuming this rate, he calculates the half-life of the collection to be approximately four- 
teen years. "That is, half of the useful collection will be in titles fourteen years old or less. The average life or life expectancy would be about twenty years old." Another finding was that "Titles over thirty years old in many college libraries comprise at least half of the collection." 44

Line and Sandison are critical of Gosnell's methodology, describing the data analyzed as having been drawn from "five well-weeded college libraries." The findings "can do little more than reveal the principles on which weeding was done." ${ }^{45}$

Jain reviewed all previous work in usage studies in an attempt to develop a mathematical model for use in selecting books for storage. ${ }^{46}$ The relevance of his study is that he is one of the few researchers to prefer age as a criterion for weeding rather than use. From his review and study he concluded:

In spite of the recent tendencies to overemphasize usage histories, this study shows that age is a significant variable in studying use of monographs ... while usage rates of individual monographs have considerable variation even over a short period of time, the usage rates of various age groups do not show any significant differences over time. ${ }^{47}$

The study that has the most relevant findings for the interpretation of median age and obsolescence rates by discipline was conducted by George V. Hodowanec. He sought to establish obsolescence rates of the monographic literature by discipline for use in academic libraries through a study to determine annual book obsolescence rates at the University of Akron in the early 1980s. ${ }^{48}$ Hodowanec sought to develop a Priority Weighting Formula (APW) for book budget allocation. The formula was based on determining annual book obsolescence rates for individual instructional departments within a university. The obsolescence rates were calculated through defining periods of "peak use," which reveals the "immediacy" of user need, and the magnitude of peak use, which reveals the "intensity" of user need. These factors were incorporated into an Obsolescence Analysis Matrix to calculate the percent of annual decline in use by four major disciplinary divisions and more specific disciplines. The study found a range in obsolescence rates by subject discipline from a low of 2.27 percent a year in foreign languages to a high of 8.50 percent in the business collection. For the major divisions, the percentage obsolescence rates per year were:

- fine arts and humanities, 4.27 percent;

- life sciences, 4.36 percent;

- pure and applied sciences, 4.38 percent;

- social and behavioral sciences, 4.69 percent.

The overall average library obsolescence rate was 4.64 percent a year. ${ }^{49}$ Thus, according to the findings of the Hodowanec study, close to five percent of a collection becomes obsolescent each year.

Although the percentage rates of obsolescence per year in his study were derived from one case study on a medium-sized, four-year institution, Hodowanec's findings can be used to suggest that an average withdrawal rate of five percent a year is reasonable for any collection in which currency of information is a priority. Indeed, the ACRL/ AECT Standards suggest a three to five percent withdrawal rate a year:

6.4 Obsolete, worn-out, and inappropriate materials should be removed based on a policy statement. Commentary. Deselection and weeding on a regular basis is indispensable to a useful collection and should be done systematically. A written policy should govern what should be removed, what should be replaced, and what should be permanently retained. Not only do obsolete and inappropriate materials occupy expensive storage space, but they also detract from other current materials containing important information. From three to five percent of the collection should be replaced annually. The 
condition of the collection should be reviewed regularly and needed repairs should be made. ${ }^{50}$

From his findings Hodowanec formed several conclusions that are relevant to consideration of currency in library materials by discipline. These are similar to the hypotheses posed by Line and Sandison. He observed that:

... substantial growth and expansion of theory, research, and publication in a particular instructional field (e.g., business) seem to result in a higher annual rate of book obsolescence for that field's curriculum-supporting collection ... Moreover, academic fields which are in a developmental or redevelopmental state, undergoing refinements in methodology and technology of their informational domain (e.g., industrial education, home economics, and computer science) tend likewise, to demonstrate higher than average rates of obsolescence in their collections. Conversely, academic fields that rely upon revised versions or new editions of already existing materials (e.g., English) tend to amass collections with below average annual obsolescence rates. Finally, certain instructional fields and certain curriculum offerings are primarily textbook oriented. When these fields and courses do not exhibit rapid expansion of theory, research, and publication, their curriculum-supporting collections tend to have below average annual use and obsolescence. ${ }^{51}$

The findings in the study by Hodowanec are similar to those by Gosnell forty years earlier. Both sought to develop formulas for calculating obsolescence by discipline based on use, and both found an average overall library obsolescence rate to be near five percent a year. Although each used a different formula for calculating obsolescence by discipline, their findings are in agreement, for the most part, in that the scholarly research disciplines such as history, literature, and math have lower obsolescence rates than the professional and applied fields, such as business and technical fields.

This review of the research in obsolescence and weeding has shown that very few studies have sought to establish obsolescence rates for monographic resources by fields or disciplines. The accepted procedures for weeding of collections have employed use or "last circulation date" as a primary criterion for deselection, rather than the age of the material. Although Line and Sandison define obsolescence in terms of both validity and use of information, the research in obsolescence and weeding has concentrated almost solely on use rather than validity of contents. The contents or quality of the information in the book receives less attention than the objective factor of use. The assumption is that low use equates with outdated content- the reason the materials are not being used. But the contents may or may not be outdated information or research. Obviously, a book cannot contain information on events or developments after its publication date, but an older edition may not necessarily contain inaccurate information, just not up-todate information; and it can still be "useful." Use of materials may or may not be related to the currency or accuracy of the information contained in a given title. Many outdated and inaccurate texts are circulating from libraries of all sizes and types because they are what the user finds on the shelf. Indeed, one of the objectives of bibliographic instruction programs is to teach students the value of determining the currency and accuracy of information, rather than just checking out any book on an assigned topic. These points were summarized by Line and Sandison:

Knowledge is commonly recorded in documents and in studying changes in their validity or utility it has been usual to study what happens to documents, although the nature of the relation between document use and information utility over time remains 
obscure. Decline in document use can occur even though the information recorded is still valid and potentially useful; it is not possible to tell from decline in document use which type of 'knowledge obsolescence' is occurring-changes in use do not necessarily correspond to changes in value and validity. Studies of document use can therefore serve only as partial indicators of "knowledge obsolescence. $^{\prime 52}$

Collection assessment is concerned with quality. With the exception of the studies by Gosnell and Hodowanec, the findings of research in obsolescence for monographic literature do not form a firm basis for considerations of median age in library collections. For the most part, the contemporary collection manager is left to fall back on what Gapen and Milner term "transmogrified bibliofolklore" in analyzing age data for library collections and forming judgments about the proper ratios of current to retrospective materials. The interpretations in the analysis of the age data by subject in the Florida Community College Collection Assessment study are based on research findings reviewed here, augmented by "bibliofolklore."

\section{Interpretation of Findings}

The rationale for the interpretation of the findings in the Florida Community College Collection Assessment Project is congruent with the philosophy that college collections should emphasize the instructional and curricular needs of students and, therefore, that the collections should emphasize current resources rather than retrospective depth. The interpretation concentrates on the findings for median age and the broader analysis of the distribution of monograph records in the LINCC aggregated resources base by subject and age.

\section{Median Age}

The median age calculation in the Florida Community College Collection Assessment Study uses 1970 as a base year. All pre-1970 titles are counted as 1970 because individual title ages prior to that date are unavailable in the study data. The calculation is performed using the number of titles in the five-year time blocks defined for the study. Actual median age of the collections would be older if median age were calculated on an individual title and year basis. The findings with respect to median age of the collective monographic resources of the Florida community colleges are displayed in table 1 and figure 1.

For the LINCC database, the overall median age is close to twenty-four years. Half of the titles were published before 1974 and half after 1974. Median age for the collective resources base ranges from a low of nineteen years for the sciences to a high of twenty-eight years in the general category. All the median ages are in the 1970s. Whereas twenty-six years for a median age may not be cause for concern in the humanities, twenty-three years appears to be high for the social sciences, which include business, psychology, education, political science, and law.

\section{Withdrawing older materials can lower the median age of a category.}

The sciences have a median age of nineteen years, but technology has a median age of twenty-one years. Although many older standard texts in the basic sciences may still be useful, the materials in the applied engineering and technological fields should be current for those fields. Although the sciences and technology have lower median ages than the humanities and social sciences, the median ages for all the broad subject groupings appear to be high.

The twenty-eight community colleges are grouped into three peer groups by size of institution. Figure 1 shows median age in the broad subject groupings for the LINCC aggregated database and the three peer groups. Although there are slight differences in the median ages among the peer groups and LINCC, they are not pronounced. Within the three peer groups, individual colleges have higher or lower median ages than the average for LINCC 


\begin{tabular}{|lcc|}
\hline & TABLE 1 \\
& LINCC Monographic Bibliographic Records by & Median Age \\
\hline \hline Subject & Year Reached 50\% & Median Age in Years \\
\hline General & 1970 & 27.76 \\
Humanities & 1971 & 26.44 \\
Social Sciences & 1975 & 22.97 \\
Sciences & 1978 & 19.19 \\
Technology & 1976 & 21.31 \\
\hline LINCC total & 1974 & 23.59 \\
\hline
\end{tabular}

and the group. For many institutions, the median age of materials corresponds to founding date and funding patterns.

For the collective resources base, fully half the material is in titles published before 1974. It would seem that if material is to be considered "current," median age should be closer to the mid-1980s in order for one-half of the collections to be less than fifteen years old. One effect of high median age is that it means the percentage of current materials is low. Withdrawing older materials can lower the median age of a category. Conversely, not weeding older materials raises the median age un- less acquisitions of newer materials increase to offset the "weight" of the older materials. This effect is readily apparent in the full data analysis by percentage distribution of the collection according to subjects and age in the next section.

\section{Percentage Distribution of Collections by}

Age

Median age is one type of analysis for age of collections. Amore detailed analysis was performed of the distribution of LINCC monographic bibliographic records according to percentage of titles for each time period for the forty-seven subjects areas de-

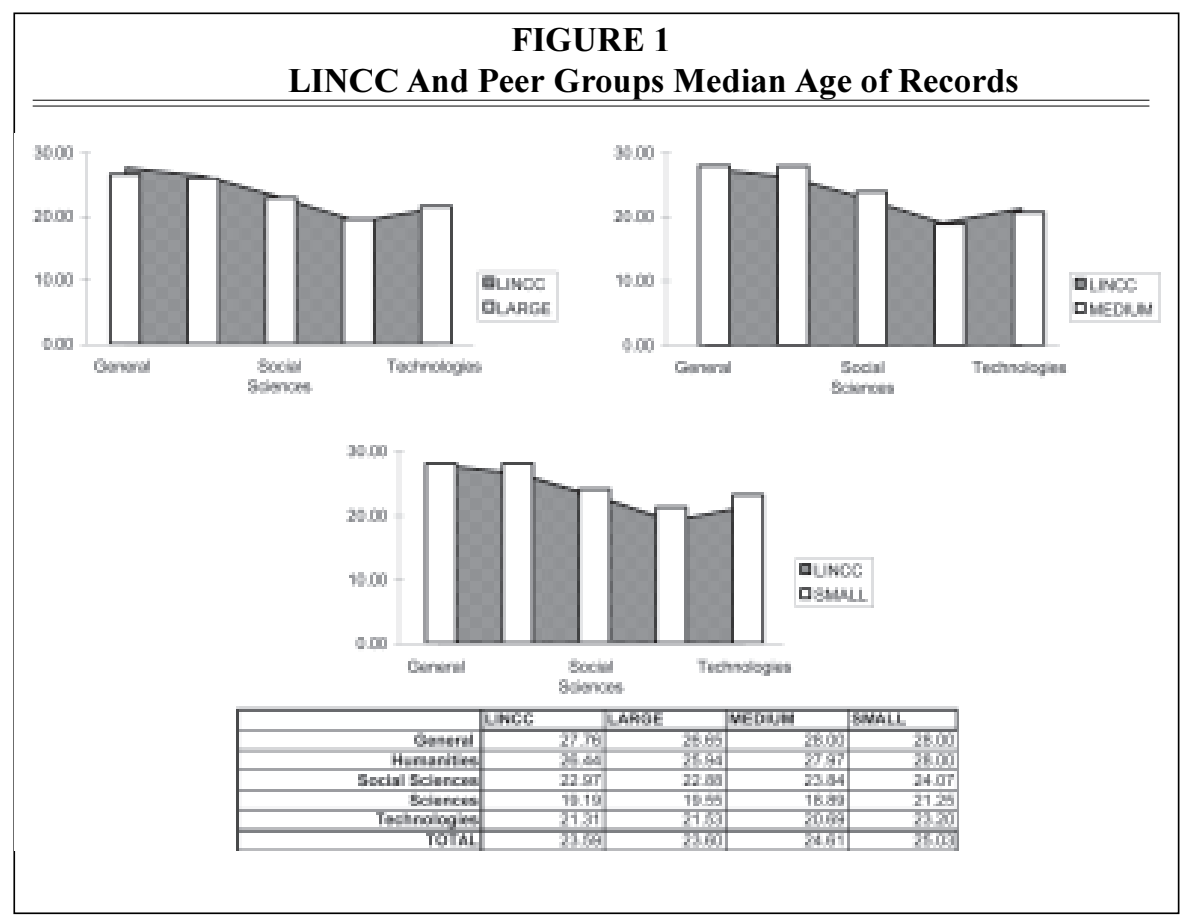


fined for the study. The results of this analysis are included in table 2 . The high percentage shares of older materials and low numbers of current acquisitions that result in low percentages of current titles show clearly in this analysis. From table 2, areas that might contain large numbers of outdated materials can be identified. Table 3 summarizes the data from table 2 by broad subject grouping across the thirtyyear time span of the study. It is easy to see why the median ages are in the 1970s by looking at the percentage distribution of records.

Reading the "LINCC average" line in table 3 horizontally from left to right, it can be seen that for the LINCC database, 36 percent of the holdings are in pre-1970 imprints. This means that as we rapidly approach the year 2000, more than onethird of the collective resources are thirty years old or older. Advancing toward the present across the bottom of the table, it can be seen that each five-year period in the analysis comprises a smaller percentage share of the total for the entire database. Although it may be cause for concern that more than one-third of the titles in the collective resources base are imprints thirty years old and older, 29 percent are in the 1970s, with another 11 percent before 1985. Thus, only 23 percent of the titles in the collective resources base are less than fifteen years old. Comparing the 1990-1994 time period with the 1970-1974 time interval, it can be seen that in all categories the older time period has a much larger percentage of records than the current time frame. Even for the sciences, the percentage of current materials is lower than for the twenty-year-old materials. Although it is desirable to have retrospective strength in some scholarly disciplines, for community colleges in which the curricula emphases are on current applied and technological fields, the collective resources show an alarming decline in numbers of new titles added in the past decade.

Although retrospective depth is desirable in the humanities, with classical texts in all fields continuing to be read, new critical and reference apparatus are necessary for current teaching in any field. Table 3 shows that more than 45 percent of humanities materials in the Florida community college collections are older than thirty years and that less than 10 percent of titles in the humanities are in 1990s imprints. The humanities rank last among the broad subject groupings in the percentage of current titles. The decline in acquisitions in the humanities may be reflecting changing priorities. It is possible that humanities subjects are no longer as high a priority in the instructional programs of the community colleges as they were twenty to thirty years ago and that enrollment may now be concentrating in the allied health and technical fields.

The social sciences have one-third of titles in the pre-1970 time period. As with the humanities, the percentage of titles declines with each five-year interval moving toward the present. The number of 1990s imprints is nearly 14 percent of the total number of social sciences titles, a better proportion than in the humanities. Slightly more than a third of titles in the social sciences were published after 1980.

In the LINCC database, the sciences seem to have fared the best over the years. Although 26.76 percent of the science collections are in the pre-1970 time period, nearly 19 percent of the science titles are in 1990 imprints. The years in between 1970 and 1990 may be in need of examination as the percentage of materials in those time frames seems high. With 26 percent in 1970s imprints and another 28 percent in 1980s imprints, there is the possibility that the science collections are still retaining many books with outdated scientific information and should be examined for deselection.

As with the other broad subject groupings, percentage share of total for the technological fields does decline moving forward in time. Although the sciences have 19 percent of total share in 1990s imprints, the highest of the broad subject groupings, technology has a 12 percent share of total in 1990s imprints. Only the humanities have a lower share of total $(10 \%)$ in current materials. 
TABLE 2

Number of Monographic Bibliographic Records per Subject

by Five Year Period Showing Records per Period as a Percentage of Total Records per Subject

\begin{tabular}{|c|c|c|c|c|c|c|c|c|c|}
\hline Subject & \multicolumn{2}{|c|}{$\begin{array}{c}\text { Pre } 1970 \\
\text { Records \% of Subj. }\end{array}$} & \multicolumn{2}{|c|}{$\begin{array}{l}\text { 1970-1974 } \\
\text { Records \% of Subj. }\end{array}$} & \multicolumn{2}{|c|}{$\begin{array}{l}\text { 1975-1979 } \\
\text { Records \% of Subj. }\end{array}$} & \multicolumn{3}{|c|}{$\begin{array}{c}1980-1984 \\
\text { Records \% of Subj. }\end{array}$} \\
\hline Total General & 3,728 & $49.56 \%$ & 694 & $9.23 \%$ & 814 & $10.82 \%$ & & 622 & $8.27 \%$ \\
\hline Philosophy & 17,967 & $55.28 \%$ & 4,467 & $13.74 \%$ & 3,292 & $10.13 \%$ & & 2,203 & $6.78 \%$ \\
\hline Religion & 24,239 & $44.49 \%$ & 7,834 & $14.38 \%$ & 6,344 & $11.64 \%$ & & 5,087 & $9.34 \%$ \\
\hline Music & 15,865 & $40.66 \%$ & 6,552 & $16.79 \%$ & 5,784 & $14.82 \%$ & & 4,210 & $10.79 \%$ \\
\hline Arts & 30,957 & $40.55 \%$ & 12,618 & $16.53 \%$ & 10,524 & $13.79 \%$ & & 8,101 & $10.61 \%$ \\
\hline Architecture & 4,848 & $38.44 \%$ & 1,766 & $14.00 \%$ & 2,031 & $16.10 \%$ & & 1,418 & $11.24 \%$ \\
\hline Lang. \& Lit. except.. & 73,045 & $51.17 \%$ & 25,470 & $17.84 \%$ & 20,096 & $14.08 \%$ & & 9,361 & $6.56 \%$ \\
\hline Romance \& Germanic Langs. & 2,321 & $53.93 \%$ & 513 & $11.92 \%$ & 361 & $8.39 \%$ & & 358 & $8.32 \%$ \\
\hline Literary History \& Collections & 32,639 & $40.74 \%$ & 12,439 & $15.52 \%$ & 10,692 & $13.34 \%$ & & 8,876 & $11.08 \%$ \\
\hline Literature: Romance Langs. & 17,373 & $58.81 \%$ & 3,825 & $12.95 \%$ & 2,569 & $8.70 \%$ & & 1,869 & $6.33 \%$ \\
\hline Subject & & $\begin{array}{l}1985 \\
\text { Records }\end{array}$ & $\begin{array}{l}-1989 \\
\% \text { of Subj. }\end{array}$ & $\begin{array}{r}1990-1 \\
\text { Records \% }\end{array}$ & $\begin{array}{l}1994 \\
\% \text { of Subj. }\end{array}$ & $\begin{array}{r}1995- \\
\text { Records \% }\end{array}$ & $\begin{array}{l}-1998 \\
\% \text { of Subj. }\end{array}$ & & $\begin{array}{l}\text { TOTAL } \\
\text { Records }\end{array}$ \\
\hline Total General & & 2,018 & $6.21 \%$ & 1,787 & $5.50 \%$ & 764 & $2.35 \%$ & & 32,502 \\
\hline Philosophy & & 4,786 & $8.78 \%$ & 4,200 & $7.71 \%$ & 1,986 & $3.64 \%$ & & 54,486 \\
\hline Religion & & 3,240 & $8.30 \%$ & 2,351 & $6.03 \%$ & 1,005 & $2.58 \%$ & & 39,020 \\
\hline Music & & 7,028 & $9.21 \%$ & 5,088 & $6.66 \%$ & 2,013 & $2.64 \%$ & & 76,341 \\
\hline Arts & & 1,364 & $10.82 \%$ & 856 & $6.79 \%$ & 328 & $2.60 \%$ & & 12,612 \\
\hline Architecture & & 7,445 & $5.22 \%$ & 5,407 & $3.79 \%$ & 1,886 & $1.32 \%$ & & 142,740 \\
\hline Lang. \& Lit. except... & & 360 & $8.36 \%$ & 305 & $7.09 \%$ & 86 & $2.00 \%$ & & 4,304 \\
\hline Romance \& Germanic Langs. & & 7,450 & $9.30 \%$ & 5,849 & $7.30 \%$ & 2,178 & $2.72 \%$ & & 80,125 \\
\hline Literary History \& Collections & & 7,450 & $9.30 \%$ & 5,849 & $7.30 \%$ & 2,178 & $2.72 \%$ & & 80,125 \\
\hline Literature: Romance Langs. & & 2,130 & $7.21 \%$ & 1,413 & $4.78 \%$ & 352 & $1.19 \%$ & & 29,539 \\
\hline
\end{tabular}




\begin{tabular}{|c|c|c|c|c|c|c|c|c|}
\hline \multirow[b]{2}{*}{ Subject } & \multicolumn{8}{|c|}{$\begin{array}{l}\text { TABLE } 2 \text { (cont.) } \\
\text { caphic Bibliographic Records per Subject } \\
\text { ds per Period as a Percentage of Total Records per Subject }\end{array}$} \\
\hline & \multicolumn{2}{|c|}{$\begin{array}{l}\text { Pre } 1970 \\
\text { Records \% of Subj. }\end{array}$} & \multicolumn{2}{|c|}{$\begin{array}{l}\text { 1970-1974 } \\
\text { Records \% of Subj. }\end{array}$} & \multicolumn{2}{|c|}{$\begin{array}{l}\text { 1975-1979 } \\
\text { Records \% of Subj. }\end{array}$} & \multicolumn{2}{|c|}{$\begin{array}{c}1980-1984 \\
\text { Records \% of Subj. }\end{array}$} \\
\hline Literature: English & 60,271 & $53.62 \%$ & 14,473 & $12.88 \%$ & 9,819 & $8.74 \%$ & 9,471 & $8.43 \%$ \\
\hline Literature: American & 54,223 & $37.40 \%$ & 17,112 & $11.80 \%$ & 12,897 & $8.90 \%$ & 17,660 & $12.18 \%$ \\
\hline Photography & 1,413 & $15.02 \%$ & 1,967 & $20.90 \%$ & 2,187 & $23.24 \%$ & 1,689 & $17.95 \%$ \\
\hline Total Humanities & 335,161 & $\mathbf{4 5 . 3 9 \%}$ & 109,036 & $14.77 \%$ & 86,596 & $11.73 \%$ & 70,303 & $9.52 \%$ \\
\hline Psychology & 12,027 & $28.49 \%$ & 7,239 & $17.15 \%$ & 7,915 & $18.75 \%$ & 5,182 & $12.27 \%$ \\
\hline Aux. Sciences of History & 8,853 & $47.68 \%$ & 2,903 & $15.64 \%$ & 2,092 & $11.27 \%$ & 1,676 & $9.03 \%$ \\
\hline History except... & 66,771 & $49.25 \%$ & 20,854 & $15.38 \%$ & 14,159 & $10.44 \%$ & 11,386 & $8.40 \%$ \\
\hline U.S. & 48,904 & $44.35 \%$ & 19,462 & $17.65 \%$ & 11,579 & $10.50 \%$ & 8,410 & $7.63 \%$ \\
\hline Americas & 22,200 & $46.39 \%$ & 7,423 & $15.51 \%$ & 5,885 & $12.30 \%$ & 3,902 & $8.15 \%$ \\
\hline Geography & 4,673 & $35.60 \%$ & 2,029 & $15.46 \%$ & 1,696 & $12.92 \%$ & 1,254 & $9.55 \%$ \\
\hline \multicolumn{2}{|l|}{ Subject } & \multicolumn{2}{|c|}{ 1985-1989 } & \multicolumn{2}{|c|}{ 1990-1994 } & \multicolumn{2}{|c|}{$\begin{array}{c}1995-1998 \\
\text { Records \% of Subj. }\end{array}$} & $\begin{array}{l}\text { TOTAL } \\
\text { Records }\end{array}$ \\
\hline Literature: English & & 10,199 & $9.07 \%$ & 5,797 & $5.16 \%$ & 2,354 & $2.09 \%$ & 112,399 \\
\hline Literature: American & & 18,938 & $13.06 \%$ & 15,963 & $11.01 \%$ & 8,159 & $5.63 \%$ & 144,965 \\
\hline Photography & & 1,083 & $11.51 \%$ & 760 & $8.08 \%$ & 310 & $3.29 \%$ & 9,410 \\
\hline Total Humanities & & 30,220 & $11.33 \%$ & 22,520 & $8.44 \%$ & 10,823 & $4.06 \%$ & 266,774 \\
\hline$\overline{\text { Psychology }}$ & & 4,112 & $9.74 \%$ & 3,739 & $8.86 \%$ & 2,000 & $4.74 \%$ & 42,219 \\
\hline Aux. Sciences of History & & 1,342 & $7.23 \%$ & 1,109 & $5.97 \%$ & 584 & $3.15 \%$ & 18,567 \\
\hline History except... & & 10,566 & $7.79 \%$ & 8,486 & $6.26 \%$ & 3,352 & $2.47 \%$ & 135,588 \\
\hline U.S. & & 8,365 & $7.59 \%$ & 9,220 & $8.36 \%$ & 4,323 & $3.92 \%$ & 110,279 \\
\hline Americas & & 3,708 & $7.75 \%$ & 3,451 & $7.21 \%$ & 1,267 & $2.65 \%$ & 47,850 \\
\hline Geography & & 1,498 & $11.41 \%$ & 1,455 & $11.08 \%$ & 519 & $3.95 \%$ & 13,128 \\
\hline
\end{tabular}




\begin{tabular}{|c|c|c|c|c|c|c|c|c|}
\hline \multirow[b]{2}{*}{ Subject } & \multicolumn{7}{|c|}{$\begin{array}{l}\text { TABLE } 2 \text { (cont.) } \\
\text { phic Bibliographic Records per Subject } \\
\text { per Period as a Percentage of Total Records per Subject }\end{array}$} & \\
\hline & \multicolumn{2}{|c|}{$\begin{array}{c}\text { Pre } 1970 \\
\text { Records \% of Subj. }\end{array}$} & \multicolumn{2}{|c|}{$\begin{array}{c}\text { 1970-1974 } \\
\text { Records \% of Subj. }\end{array}$} & \multicolumn{2}{|c|}{$\begin{array}{l}\text { 1975-1979 } \\
\text { Records \% of Subj. }\end{array}$} & \multicolumn{2}{|c|}{ 1980-1984 } \\
\hline Anthropology & 7,170 & $33.66 \%$ & 3,927 & $18.44 \%$ & 3,476 & $16.32 \%$ & 2,209 & $10.37 \%$ \\
\hline Recreation & 7,738 & $25.48 \%$ & 5,529 & $18.21 \%$ & 6,565 & $21.62 \%$ & 4,286 & $14.11 \%$ \\
\hline Social Sciences, General & 7,738 & $5.30 \%$ & 681 & $2.24 \%$ & 647 & $2.13 \%$ & 590 & $1.94 \%$ \\
\hline Business, Finance \& Economics & 1,608 & $23.84 \%$ & 19,479 & $14.39 \%$ & 21,043 & $15.55 \%$ & 20,323 & $15.02 \%$ \\
\hline Sociology & 32,259 & $19.59 \%$ & 21,633 & $17.88 \%$ & 21,383 & $17.67 \%$ & 16,485 & $13.63 \%$ \\
\hline Political Science & 23,707 & $43.86 \%$ & 8,070 & $16.09 \%$ & 6,113 & $12.19 \%$ & 5,124 & $10.22 \%$ \\
\hline Law & 21,994 & $21.16 \%$ & 7,916 & $16.64 \%$ & 7,996 & $16.81 \%$ & 6,617 & $13.91 \%$ \\
\hline Education & 10,064 & $27.94 \%$ & 16,312 & $19.26 \%$ & 12,262 & $14.48 \%$ & 9,460 & $11.17 \%$ \\
\hline Military \& Naval Science & 23,659 & $28.92 \%$ & 2,207 & $13.61 \%$ & 2,054 & $12.66 \%$ & 2,901 & $17.88 \%$ \\
\hline Bibliography \& Library Science & 4,691 & $23.90 \%$ & 5,167 & $15.76 \%$ & 5,420 & $16.53 \%$ & 4,957 & $15.12 \%$ \\
\hline Subject & \multicolumn{3}{|c|}{$\begin{array}{l}\text { 1985-89 } \\
\text { Records \% of Subj. }\end{array}$} & \multicolumn{2}{|c|}{$1990-94$} & \multicolumn{2}{|c|}{ 1995-98 } & $\begin{array}{l}\text { TOTAL } \\
\text { Records }\end{array}$ \\
\hline Anthropology & & 1,934 & $9.08 \%$ & 1,857 & $8.72 \%$ & 721 & $3.38 \%$ & 21,301 \\
\hline Recreation & & 2,911 & $9.59 \%$ & 2,289 & $7.54 \%$ & 1,042 & $3.43 \%$ & 30,367 \\
\hline Social Sciences, General & & 2,911 & $10.24 \%$ & 351 & $7.83 \%$ & 146 & $3.26 \%$ & 4,482 \\
\hline Business, Finance \& Economics & & 459 & $13.26 \%$ & 16,550 & $12.23 \%$ & 7,728 & $5.71 \%$ & 135,339 \\
\hline Sociology & & 17,940 & $12.31 \%$ & 14,412 & $11.91 \%$ & 8,471 & $7.00 \%$ & 120,985 \\
\hline Political Science & & 14,889 & $7.50 \%$ & 3,557 & $7.09 \%$ & 1,518 & $3.03 \%$ & 50,146 \\
\hline Law & & 3,759 & $13.44 \%$ & 5,896 & $12.39 \%$ & 2,683 & $5.64 \%$ & 47,569 \\
\hline Education & & 6,391 & $10.25 \%$ & 9,136 & $10.79 \%$ & 5,154 & $6.09 \%$ & 84,675 \\
\hline Military \& Navel Science & & 8,682 & $17.21 \%$ & 1,135 & $7.00 \%$ & 435 & $2.68 \%$ & 16,221 \\
\hline Bibliography \& Library Science & & 2,791 & $13.41 \%$ & 3,536 & $10.78 \%$ & 1,464 & $4.47 \%$ & 32,787 \\
\hline
\end{tabular}




\begin{tabular}{|c|c|c|c|c|c|c|c|c|}
\hline \multirow[b]{2}{*}{ Subject } & \multicolumn{7}{|c|}{$\begin{array}{l}\text { TABLE } 2 \text { (cont.) } \\
\text { Number of Monographic Bibliographic Records per Subject } \\
\text { Period Showing Records per Period as a Percentage of Total Records per Subject }\end{array}$} & \\
\hline & \multicolumn{2}{|c|}{$\begin{array}{c}\text { Pre } 1970 \\
\text { Records \% of Subj }\end{array}$} & \multicolumn{2}{|c|}{$\begin{array}{c}\text { 1970-1974 } \\
\text { Records \% of Subj. }\end{array}$} & \multicolumn{2}{|c|}{$\begin{array}{l}\text { 1975-1979 } \\
\text { Records \% of Subj. }\end{array}$} & \multicolumn{2}{|c|}{$\begin{array}{c}1980-1984 \\
\text { Records \% of Subj. }\end{array}$} \\
\hline Total Social Sciences & 304,153 & $33.37 \%$ & 150,831 & $16.55 \%$ & 130,285 & $14.29 \%$ & 104,762 & $11.49 \%$ \\
\hline Oceanography & 596,182 & $0.12 \%$ & 604 & $0.07 \%$ & 329 & $0.04 \%$ & 249 & $0.03 \%$ \\
\hline Science, General & 1,130 & $41.11 \%$ & 1,517 & $12.71 \%$ & 1,136 & $9.52 \%$ & 1,329 & $11.14 \%$ \\
\hline Mathematics & 4,907 & $30.81 \%$ & 4,024 & $10.80 \%$ & 3,659 & $9.82 \%$ & 6,139 & $16.47 \%$ \\
\hline Physical Sciences & 11,483 & $41.08 \%$ & 6,827 & $14.62 \%$ & 5,722 & $12.25 \%$ & 5,501 & $11.78 \%$ \\
\hline Life Sciences & 19,186 & $40.02 \%$ & 9,983 & $17.52 \%$ & 7,753 & $13.61 \%$ & 5,621 & $9.86 \%$ \\
\hline Anatomy, Physiology \& Microbiology & 22,806 & $23.33 \%$ & 3,548 & $13.70 \%$ & 4,301 & $16.61 \%$ & 3,721 & $14.37 \%$ \\
\hline Medicine & 6,043 & $10.42 \%$ & 8,722 & $10.80 \%$ & 12,611 & $15.61 \%$ & 13,801 & $17.08 \%$ \\
\hline Therapeutics \& Pharmacology & 8,417 & $8.37 \%$ & 778 & $9.68 \%$ & 1,087 & $13.52 \%$ & 1,328 & $16.52 \%$ \\
\hline Nursing & 673 & $0.78 \%$ & 748 & $6.68 \%$ & 1,222 & $10.92 \%$ & 2,125 & $18.99 \%$ \\
\hline Subject & & $\begin{array}{r}198 \\
\text { Records } \\
\end{array}$ & $\begin{array}{l}\text { 35-89 } \\
\% \text { of Subj. }\end{array}$ & $\begin{array}{r}1990-19 \\
\text { Records \% } \\
\end{array}$ & $\begin{array}{l}1994 \\
\text { o of Subj. }\end{array}$ & $\begin{array}{r}1995-1 \\
\text { Records \% } \\
\end{array}$ & $\begin{array}{l}-1998 \\
\% \text { of Subj. }\end{array}$ & $\begin{array}{l}\text { TOTAL } \\
\text { Records } \\
\end{array}$ \\
\hline Total Social Sciences & & 93,745 & $10.28 \%$ & 86,179 & $9.45 \%$ & 41,407 & $4.54 \%$ & 911,503 \\
\hline Oceanography & & 0 & $12.89 \%$ & 1,051 & $8.81 \%$ & 456 & $3.82 \%$ & 11,935 \\
\hline Science, General & & 184 & $14.48 \%$ & 4,505 & $12.09 \%$ & 2,070 & $5.55 \%$ & 37,276 \\
\hline Mathematics & & 1,539 & $9.49 \%$ & 3,542 & $7.58 \%$ & 1,489 & $3.19 \%$ & 46,701 \\
\hline Physical Sciences & & 5,396 & $8.86 \%$ & 3,982 & $6.99 \%$ & 1,787 & $3.14 \%$ & 56,984 \\
\hline Life Sciences & & 4,432 & $13.02 \%$ & 3,171 & $12.24 \%$ & 1,735 & $6.70 \%$ & 25,901 \\
\hline Anatomy, Physiology \& Microbiology & & 5,046 & $18.98 \%$ & 14,371 & $17.79 \%$ & 7,532 & $9.32 \%$ & 80,790 \\
\hline Medicine & & 3,372 & $21.23 \%$ & 1,629 & $20.27 \%$ & 836 & $10.40 \%$ & 8,037 \\
\hline Therapeutics \& Pharmacology & & 15,333 & $0.00 \%$ & 2,650 & $23.68 \%$ & 1,479 & $13.22 \%$ & 11,191 \\
\hline Nursing & & 1,706 & $0.00 \%$ & 89 & $14.54 \%$ & 99 & $16.18 \%$ & 612 \\
\hline
\end{tabular}




\begin{tabular}{|c|c|c|c|c|c|c|c|c|c|}
\hline \multicolumn{10}{|c|}{$\begin{array}{l}\text { ecords per Subject } \\
\text { entage of Total Records per Subject }\end{array}$} \\
\hline Subject & \multicolumn{2}{|c|}{$\begin{array}{c}\text { Pre } 1970 \\
\text { Records \% of Subj }\end{array}$} & \multicolumn{3}{|c|}{$\begin{array}{c}\text { 1970-1974 } \\
\text { Records \% of Subj. }\end{array}$} & \multicolumn{2}{|c|}{$\begin{array}{l}\text { 1975-1979 } \\
\text { Records \% of Subj. }\end{array}$} & \multicolumn{2}{|c|}{$\begin{array}{c}\text { 1980-1984 } \\
\text { Records \% of Subj. }\end{array}$} \\
\hline Other Systems of Medicine & 87 & $14.22 \%$ & & 70 & $11.44 \%$ & 88 & $14.38 \%$ & 97 & $15.85 \%$ \\
\hline Total Sciences & 75,629 & $26.76 \%$ & & $\overline{6,821}$ & $13.03 \%$ & 37,908 & $13.41 \%$ & 39,911 & $14.12 \%$ \\
\hline Agriculture & 7,164 & $29.99 \%$ & & 4,654 & $19.48 \%$ & 4,486 & $18.78 \%$ & 2,699 & $11.30 \%$ \\
\hline Technology: General & 1,944 & $26.19 \%$ & & 1,070 & $14.42 \%$ & 1,082 & $14.58 \%$ & 1,064 & $14.34 \%$ \\
\hline Engineering: General, Civil, Construction & 4,622 & $21.72 \%$ & & 4,067 & $19.11 \%$ & 4,205 & $19.76 \%$ & 3,253 & $15.29 \%$ \\
\hline Engineering: Mechanical & 1,380 & $25.93 \%$ & & 676 & $12.70 \%$ & 1,384 & $26.00 \%$ & 1,069 & $20.08 \%$ \\
\hline Engineering: Electrical & 3,977 & $24.49 \%$ & & 2,307 & $14.21 \%$ & 2,526 & $15.56 \%$ & 2,599 & $16.01 \%$ \\
\hline Engineering: Automotive, Aeronautical & 3,683 & $28.38 \%$ & & 2,339 & $18.03 \%$ & 2,467 & $19.01 \%$ & 1,720 & $13.26 \%$ \\
\hline Mining, Metalurgy, Chem. Tech. & 1,791 & $36.60 \%$ & & 1,029 & $21.03 \%$ & 739 & $15.10 \%$ & 673 & $13.75 \%$ \\
\hline Manufactures \& Handicrafts & 3,217 & $21.11 \%$ & & 3,541 & $23.23 \%$ & 3,871 & $25.40 \%$ & 2,075 & $13.62 \%$ \\
\hline \multicolumn{2}{|l|}{ Subject } & \multicolumn{3}{|c|}{$\begin{array}{c}\text { 1985-1989 } \\
\text { Records \% of Subj. }\end{array}$} & \multicolumn{2}{|c|}{$\begin{array}{c}1990-1994 \\
\text { Records \% of Subj. }\end{array}$} & \multicolumn{2}{|c|}{$\begin{array}{l}\text { 1995-1998 } \\
\text { Records \% of Subj. }\end{array}$} & $\begin{array}{l}\text { TOTAL } \\
\text { Records }\end{array}$ \\
\hline Other Systems of Medicine & & 82 & $13.40 \%$ & & 89 & $14.54 \%$ & 99 & $16.18 \%$ & 612 \\
\hline Total Sciences & & 39,160 & $13.85 \%$ & & 35,383 & $12.52 \%$ & 17,828 & $6.31 \%$ & 282,661 \\
\hline Agriculture & & 2,400 & $10.05 \%$ & & 1,736 & $7.27 \%$ & 749 & $3.14 \%$ & 23,888 \\
\hline Technology: General & & 971 & $13.08 \%$ & & 881 & $11.87 \%$ & 407 & $5.48 \%$ & 7,422 \\
\hline Engineering: General, Civil, Constructio & & 2,364 & $11.11 \%$ & & 2,167 & $10.18 \%$ & 596 & $2.80 \%$ & 21,278 \\
\hline Engineering: Mechanical & & 456 & $8.57 \%$ & & 276 & $5.19 \%$ & 81 & $1.52 \%$ & 5,323 \\
\hline Engineering: Electrical & & 1,995 & $12.29 \%$ & & 1,598 & $9.84 \%$ & 1,234 & $7.60 \%$ & 16,236 \\
\hline Engineering: Automotive, Aeroautical & & 1,515 & $11.68 \%$ & & 921 & $7.10 \%$ & 330 & $2.54 \%$ & 12,976 \\
\hline Mining, Metalurgy, Chem. Tech. & & 348 & $7.11 \%$ & & 227 & $4.64 \%$ & 86 & $1.76 \%$ & 4,893 \\
\hline Manufactures \& Handicrafts & & 1,388 & $9.11 \%$ & & 783 & $5.14 \%$ & 361 & $2.37 \%$ & 15,240 \\
\hline
\end{tabular}




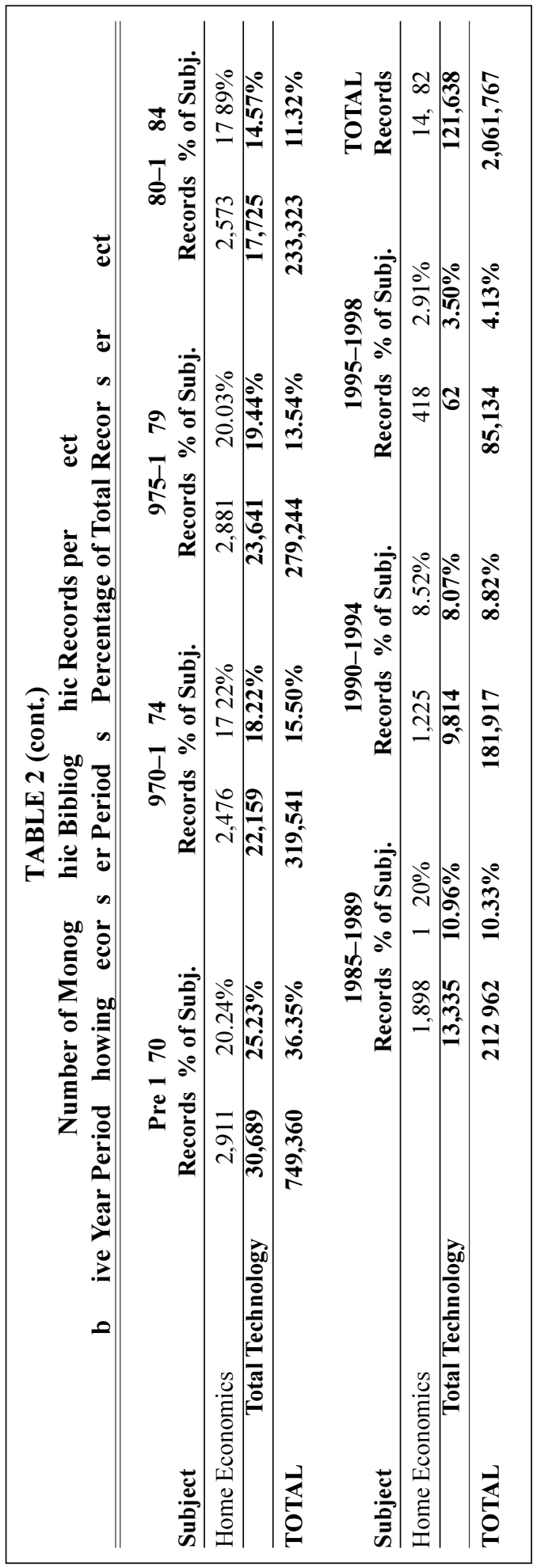

Technology does not follow the same pattern as the sciences. One reason for the differences may be that the universe of monographic publications in these fields is smaller than in the basic sciences and allied health fields. The practical nature of the education and training in the technological fields makes them less library and information resources oriented. With 25 percent of total in pre-1970 imprints, this subject grouping may need even more concentrated deselection attention.

More specific subject areas can be examined using table 2. Looking at the figures for the health sciences in table 2, it can be seen that while only 10 percent of total is in pre-1970 imprints, 26 percent concentrates in the 1970s, with 17 percent in 1980-1984, and 19 percent of total in 1985-1989. The acquisitions rate for the twenty-year period 1970-1989 appears to have been adequate, but many of the applied materials from that time span would now be outdated practice, especially those before 1985, now almost fifteen years old.

The general, physical, and life sciences all have more than 40 percent of total in pre-1970 imprints, with mathematics at 30 percent and oceanography at 35 percent. The latter two subject areas display a more erratic acquisitions pattern over time, increasing share of total in some years and decreasing in others. In the 1990s, the positions of the subject areas in the sciences are somewhat reversed from earlier decades, with the health sciences fields occupying larger proportions of total and the basic sciences declining in share of total.

Computer science titles classify in several different call numbersQA, TK, and in the Hs. It is especially alarming that the math (QA) and electrical engineering (TK) lines do not show a more current 
age or rate of acquisitions pattern. Mechanical engineering has the highest percentage of materials in the 1980-1998 time frame, but it still has more than 50 percent of titles in the pre-1980 time frame. In fact, fully 62 percent of titles in technology are pre-1980s imprints.

Business, education, law, and electrical engineering have larger percentages of older imprints with decreasing percentages of the total number of titles in more current years. Medicine and nursing have an opposite pattern with larger numbers of titles in more recent years and smaller percentages of titles in older materials. In fact, table 2 shows that the health sciences categories, the lines for medicine, therapeutics and pharmacology, nursing, and "other systems of medicine," have the highest percentages of total in the LINCC database of all subjects in the 1990s.

To reiterate, in the Florida community college collections, the sciences have fared better in acquisitions numbers overall than the humanities and social sciences. The main problem is in the number of older imprints that could contain outdated information, especially in the professional, technical, and scientific fields. With acquisitions slowing in the past twenty-five years, there are probably materials that contain outdated information. Many areas may need newer editions of basic, standard material.

The next section further considers the problem of age of collections as it relates to the provision of high-quality resources.

\section{Hypothetical Median Age}

As previously stated, the rationale on which the analysis for the Florida community colleges is based is that the collections be composed of materials that are intellectually viable and contain accurate, current information. It is useful to ponder what a percentage share of total for the broad subject groupings would look like if a hypothetical matrix were constructed to achieve a desirable balance of more recent books to older materials. Table 4 resembles the actual data from the Florida Community College study contained in table 3 but is constructed to take the differences in scholarship between the broad subject groupings into consideration. It is a hypothetical look at percentage share of total with an emphasis on current materials.

Table 4 illustrates a seesaw pattern. The sci/tech fields are light on the older side and "heavier" on the current end. The scholarly disciplines are tipped toward the older end, although they have a higher percentage of share in recent materials than the patterns found in the Florida community college study. The differences between the patterns of distribution by time period in the two tables is striking.

Obviously, it is simple mathematics that the percentage share of total collections post-1980 must be at least 50 percent in order to achieve median ages in the 1980s. The hypothetical distribution in table 4 would result in median ages (indicated by bold type) of the 1970s for the humanities, in the mid-1980s for the social sciences, the late 1980s for sciences, and the early 1990s for technology. Although the percentage shares could be adjusted endlessly, the percentages in the table do allow for differences in the production and use of knowledge in the broad groupings. The humanities do have the highest percentage in retrospective materials. The social sciences have one-fourth in older materi-

\begin{tabular}{|lrrrrrrrr|}
\hline \multicolumn{7}{|c|}{ TABLE 3 } \\
\multicolumn{8}{|c}{ Percentage Shares by Time Period for Broad Subject Groupings in LINCC } \\
\hline \hline & Pre 70 & $70-74$ & $75-79$ & $80-84$ & $85-89$ & $90-94$ & $95-98$ & Total \\
\hline Humanities & $45.39 \%$ & $14.77 \%$ & $11.73 \%$ & $9.52 \%$ & $8.94 \%$ & $6.74 \%$ & $2.90 \%$ & $100.00 \%$ \\
Social Sciences & $33.37 \%$ & $16.55 \%$ & $14.29 \%$ & $11.49 \%$ & $10.28 \%$ & $9.45 \%$ & $4.54 \%$ & $100.00 \%$ \\
Sciences & $26.76 \%$ & $13.03 \%$ & $13.41 \%$ & $14.12 \%$ & $13.85 \%$ & $12.52 \%$ & $6.31 \%$ & $100.00 \%$ \\
Technology & $25.23 \%$ & $18.22 \%$ & $19.44 \%$ & $14.57 \%$ & $10.96 \%$ & $8.07 \%$ & $3.50 \%$ & $100.00 \%$ \\
LINCC (avg.) & $36.35 \%$ & $15.50 \%$ & $13.54 \%$ & $11.32 \%$ & $10.33 \%$ & $8.82 \%$ & $4.13 \%$ & $100.00 \%$ \\
\hline
\end{tabular}




\begin{tabular}{|c|c|c|c|c|c|c|c|}
\hline \multicolumn{8}{|c|}{$\begin{array}{c}\text { TABLE } 4 \\
\text { Hypothetical Share of Subject Groupings to Achieve Lower Median Ages }\end{array}$} \\
\hline & Pre 1970 & $1970 \mathrm{~s}$ & $1980-84$ & 1985-89 & 1990-94 & 1995-99 & Total \\
\hline Humanities & $37 \%$ & $23 \%$ & $12 \%$ & $11 \%$ & $9 \%$ & $8 \%$ & $100 \%$ \\
\hline Social Sciences & $25 \%$ & $16 \%$ & $13 \%$ & $13 \%$ & $15 \%$ & $18 \%$ & $100 \%$ \\
\hline Sciences & $19 \%$ & $13 \%$ & $10 \%$ & $15 \%$ & $19 \%$ & $24 \%$ & $100 \%$ \\
\hline Technology & $15 \%$ & $10 \%$ & $11 \%$ & $10 \%$ & $25 \%$ & $27 \%$ & $100 \%$ \\
\hline
\end{tabular}

als to allow for the historical nature of the scholarly disciplines in the social sciences. The percentages in the last two time periods may look shockingly large for the social sciences, sciences, and technology compared to the humanities. But it must be borne in mind that these figures reflect an idealized distribution by percentage share within the four broad areas of knowledge and not annual acquisitions rates. As previously observed, the larger the percentage of older imprints in an area, the smaller the percentage of more current materials in a 100 percent calculation.

This table of a hypothetical distribution of titles by five-year periods for the broad subject groupings is meant to be thoughtprovoking. It illustrates the differences between fields and disciplines with high obsolescence rates and those with materials that remain viable for longer periods of time. This discussion has been for the purpose of raising the issue of median age and its effects on the quality of resources and impact on the services those resources provide. Although research libraries do not aim to lower the median age of collections, there are areas in professional, technical, and scientific fields that should have lower median ages than the scholarly retrospective disciplines, no matter the size of the library. Only the largest of research institutions can justify keeping outdated professional, technical, and scientific information for historical purposes.

\section{Recommendations}

The problem of high median age and insufficient numbers of current acquisitions in the Florida community college collec- tions was addressed in the LINCC Report with a proposed collection management model based on systematic additions and withdrawals-a Continual Update Model. This model is similar to the nogrowth, "optimal collection size" theory posited at the conference in Chicago in 1975 by Trueswell and further elaborated on by Daniel Gore.

The classic studies in both weeding and obsolescence had nearly all been reported by the mid-1970s. By this time, it was apparent that the rapid collection building of the 1950s, 1960s, and early 1970s, and the continued increase in the number of publications, monographs, and journals, were causing both space and budgetary problems in academic libraries. A conference was held in Chicago in 1975 to address these problems. At that meeting, Trueswell posited the idea of a no-growth collection, which he defined as a static-size collection to which new additions would still be made. ${ }^{53}$ The static size would be maintained by a steady withdrawal rate balanced with the same rate of new acquisitions. This "optimal collection size" theory was explicated by Daniel Gore in a research paper added to the conference proceedings which gave the volume and the movement an identity- “Farewell to Alexandria: Solutions to Space, Growth, and Performance Problems of Libraries." 54

Gore attempted to answer the question, How large should a library be? His answer was that a collection should be large enough to produce the performance (satisfaction) rate desired by the institution. He emphasized that an optimum performance rate could be achieved with smaller, but 
more judiciously selected, collections. His rationale was based on making the collection smaller to provide more and better service, which he termed "acceptable performance rate," which in turn was based on "availability rate" of materials the library owned. Gore's argument was that a new building would never be needed if the number of volumes required to maintain any specified performance rate also remained constant. Although the titles held by a library will change from year to year, the total number remains constant. The outflow rate of withdrawn materials will match the intake rate of new volumes. The withdrawals would be selected by the Trueswell criterion of weeding by last circulation date.

Gore based the explication for optimal collection size on a hypothetical collection of one million volumes. This theoretical model was based on the findings of previous research in obsolescence, use, and weeding. But it was not found to be practical. The no-growth concept, which would seem to have been a logical consequence of the need to control growth and weed collections, was very controversial and not accepted in the research library arena. The literature of the library field does not contain reports of the adoption of the optimal collection size model.

\section{Continual Update Model}

The Continual Update Model incorporates the finding by Hodowanec that the overall obsolescence rate for college collections is approximately five percent a year. The suggested model for collection management is to add five percent new titles a year at the same time withdrawing five percent older materials. Although this model resembles the optimal collection size theory, it does not require the calculation of performance rates, availability rates, and so on. It is not based on a predetermined or optimal collection size but, rather, on a dynamic collection of continued additions and withdrawals within which median age by discipline and field can be monitored. The emphasis is on maintaining currency of re- sources rather than a certain optimum collection size.

A recommended collection profile, using data from the LINCC study to illustrate the Continual Update Model, is shown in figure 2. The 1990-1994 time period, which is the last complete data interval in the study, is used to calculate a projection for the LINCC database through the year 2004. The graph assumes five percent additions and withdrawals on a moving five-year scale. Thus, the last three bars in the graph are the same percentage of collection because the same acquisitions level is used for all three. The bars in the main graph in figure 2 show the distribution of the existing resources according to the time periods utilized in the study. The line (shaded area) shows what the distribution by imprint date would look like had the suggested model been in practice since 1970 .

Collections in which the Continual Update Model is practiced would have an age profile almost directly the opposite of the present profile of the LINCC aggregated resources base. Over the span of nearly thirty years, the collective resources by imprint year would have had a substantially different age composition had the suggested model been in place. A systematic process of additions and withdrawals would produce a profile similar to the shaded area in figure 2. As new materials are added and older, outdated materials withdrawn, the percentage of older materials diminishes in proportion to current imprints. The median age in this hypothetical collection would have been an overall eleven years instead of the actual LINCC median age of twenty-four years.

If such a model were implemented, withdrawals would naturally be spread over the entire collection, although not evenly, but more heavily in some fields than others. The percentage of materials for specific disciplines needing replacement each year could become a factor in a formula for book budget allocations, just as Gosnell and Hodowanec had suggested.

The point of this model is not to save space, although that is one effect. Rather, 
the point is to maintain collections at a current level while at the same time retaining the intellectually viable titles in the collections and discarding superceded and justplain-wrong information. Literary texts, basic science texts, and any other materials still intellectually viable could remain or be replaced with newer editions that would be more attractive to users. Classics no longer in print could be retained and supplemented with newer critical or explicative apparatus. The net effect of such a policy is to keep collections current in areas in which currency is paramount and at the same time to maintain breadth and depth in areas in which historical material is desirable. Such collections impress users as fresh and up-to-date. They also impart to users the confidence that a college library is adequately supported by the institution and that its professionals are knowledgeable and capable of assisting them in the educational process.

The model requires that new additions to the collection be sustained at the level of at least five percent per year. Although five percent may not seem high, calculated for many academic libraries on just the monograph budget, or by number of titles acquired annually, it is, in reality, a substantial figure. The adoption of such a model could be the impetus for a longrange funding plan for college collections because implementation requires the ad-

\section{If libraries are to continue to be buildings with physical materials as well as virtual services, the collec- tions need to be vibrant and not give a warehouse impression.}

dition of, at a minimum, five percent new materials a year.

\section{Conclusions}

From the analysis in the Florida community college study, it appears there is a relationship between median age of collections, level of funding, and founding date. Most of the community colleges were founded in the 1960s. Start-up funding was adequate or more than adequate for this time period. However, by the 1980s, higher education in general was beginning to experience reduced funding or at least reduced purchasing power. In many institutions, the library / learning resources centers were simply not supported as well as other components. For these and a variety of other reasons, the collections of the community colleges in

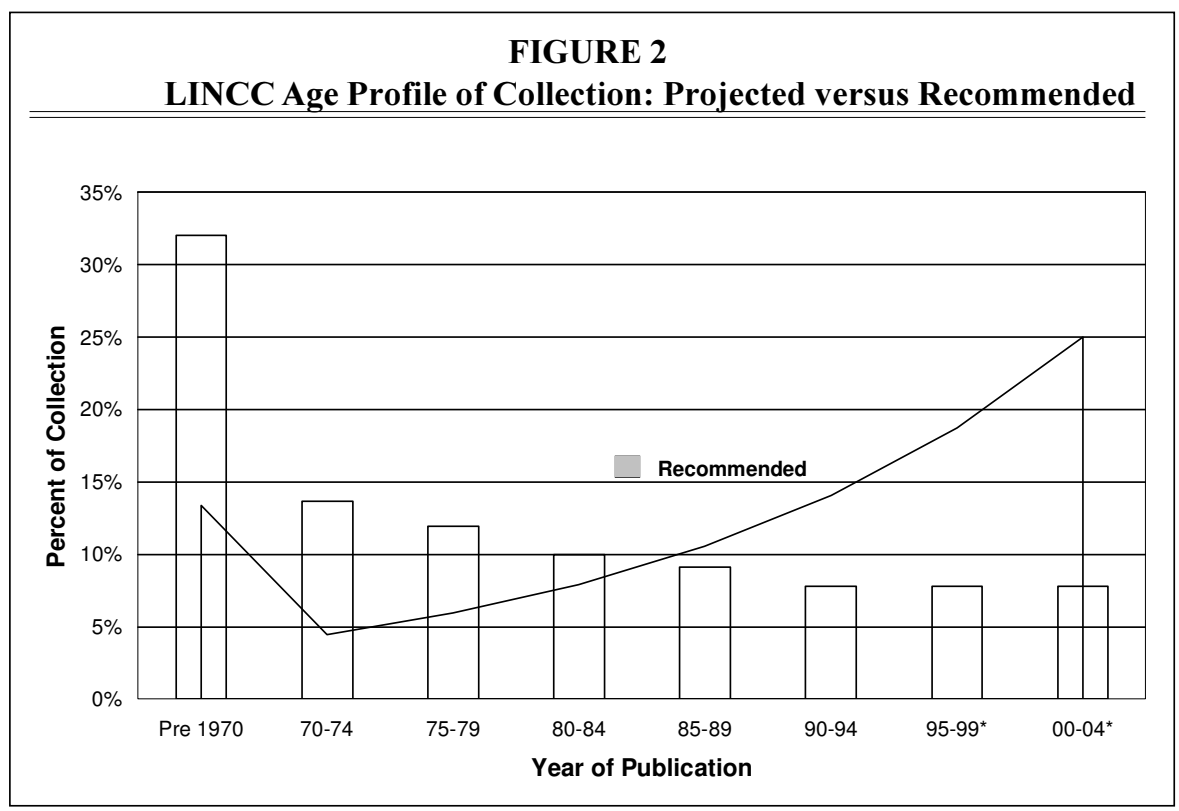


Florida experienced declining growth beginning in the late 1970s. As we move forward in time, the majority of subject areas in the study decline in acquisitions numbers resulting in median collection ages in the 1970s. The profiles of the community colleges and the collective resources base reflect an uneven pattern of support for the collections, which has resulted in high median ages and serious deficiencies in current materials.

The findings of the 1998 LINCC collection analysis have led to concern and recommendations for collection management in college library collections. As we approach the end of this decade and century, age of collections should be a measure for examination of the quality of service provided by the resources. The acquisitions buildup of the post World War Two years through the late 1970s has stocked academic libraries with materials that now are twenty to fifty years old. Have many of these materials from the peak collection building years now become outdated and too misleading to retain? Are there high median ages due to the lack of current acquisitions to bring down the "weight" of the larger percentages of older materials?

Although community colleges and undergraduate libraries have the clearest mission to emphasize and maintain current collections, with the rapid changes technology has brought to almost every professional, scientific, and technical field, currency of information is a much more paramount consideration now than it was thirty years ago when academic libraries focused on building retrospective collections to serve the future. If libraries are to continue to be buildings with physical materials as well as virtual services, the collections need to be vibrant and not give a warehouse impression. As we approach the new millennium, do we need to revise collection management thinking?

\section{Notes}

1. Association of Research Libraries, ARL Statistics, 1989/90 (Washington, D.C.: ARL 1991): 7.

2. Anna H. Perrault, "The Shrinking National Collection: A Study of the Effects of the Diversion of Funds from Monographs to Serials on the Monograph Collections of Research Libraries," Library Acquisitions Practice \& Theory 18, no. 1 (1994): 3-22; "The Changing Print Resource Base of Academic Research Libraries in the United States," JELIS (Journal of Education for Library and Information Science) 36 (fall 1995): 1-16.

3. Anna H. Perrault, John DePew, Richard Madaus, Ann Armbrister, and Jeannie Dixon, "An Assessment of the Collective Resources Base of Florida Community College Library Collections: A Profile with Interpretive Analysis," Resources Sharing and Information Networks 14, no. 1 (1999). In press.

4. Ibid.

5. W. Lee Hisle, "Program Review of the Florida Community College System Libraries/Learning Resources" (Tallahassee, Fla.: Florida Division of Community Colleges, Aug. 2, 1996), Report.

6. Anna H. Perrault, Richard Madaus, Ann Armbrister, Jeannie Dixon, and Rhonda Smith, The Florida Community College Collection Assessment: A Study of the Collections of the Twenty-Eight Florida Community College Collections (Tallahassee, Fla.: College Center for Library Automation, 1998).

7. Wanda K. Johnston, Administering the Community College Learning Resources Program (New York: G. K. Hall, 1994).

8. Ibid., 66.

9. Evan Farber, "Limiting Library Collection Growth," in Farewell to Alexandria: Solutions to Space, Growth, and Performance Problems of Libraries, ed. Daniel Gore (Westport, Conn.: Greenwood Pr., 1975), 39-40.

10. Maurice B. Line and Alexander Sandison, "'Obsolescence' and Changes in Literature over Time," Journal of Documentation 30 (Sept. 1974): 283-349.

11. Ibid., 283.

12. Ibid., 323-49.

13. Ibid., 298.

14. Ibid., 317-18.

15. Ibid., 320-21.

16. D. Kaye Gapen and Sigrid P. Milner, “Obsolescence,” Library Trends 30 (summer 1981): 107-24.

17. Ibid., 116-17. 
18. Ibid., 117.

19. Ibid., 107.

20. Ibid., 119-22.

21. Maurice B. Line, "Changes in the Use of Literature with Time-Obsolescence Revisited," Library Trends 41 (spring 1993): 665-83.

22. Ibid., 665 .

23. Ibid., 670 .

24. Ibid., 679 .

25. Dianne Rothenberg, "Changing Values in the Published Literature with Time," Library Trends 41 (spring 1993): 684-99.

26. Ibid., 694 .

27. Ibid., 697.

28. Stanley J. Slote, "Analysis and Review of the Literature of Weeding," in Weeding Library Collections, $4^{\text {th }}$ ed. (Englewood, Colo.: Libraries Unlimited, 1997), 48-79.

29. Winston C. Lister, "Least Cost Decision Rules for the Selection of Library Materials for Compact Storage" (Ph.D. diss., Purdue University, 1967).

30. Aridaman K. Jain, "A Statistical Study of Book Use Supplemented with a Bibliography of Library Use Studies" (Ph,D. diss., Purdue University, 1967); — , "Sampling and Short-Period Usage in the Purdue Library," College E Research Libraries 27 (May 1966): 211-18; __, "Sampling and Data Collection Methods for a Book-Use Study," Library Quarterly 39 (1969): 345-52.

31. Herman H. Fussler and Julian L. Simon, Patterns in the Use of Books in Large Research Libraries (Chicago: Univ. of Chicago Pr., 1969).

32. Michael K. Buckland, "Systems Analysis of a University Library," Occasional Papers, no. 4 (Lancaster, Eng.: Univ. of Lancaster Library, 1970).

33. Richard W. Trueswell, "A Quantitative Measure of User Circulation Requirements and Its Possible Effect on Stack Thinning and Multiple Copy Determination," American Documentation 16 (Jan. 1965): 20-25; _ _ "Determining the Optimal Number of Volumes for a Library's Core Collection," Libri 16 (1966): 49-60;__, Analysis of Library User Circulation Requirements (Amherst, Mass.: Univ. of Massachusetts, 1968); "User Circulation Satisfaction vs. Size of Holdings at Three Academic Libraries," College E Research Libraries 30 (May 1969): 204-13; __, "Growing Libraries: Who Needs Them? A Statistical Basis for the No-Growth Collection," in Farewell to Alexandria: Solutions to Space, Growth, and Performance Problems of Libraries, ed. Daniel Gore (Westport, Conn.: Greenwood Pr., 1975): 72-104. (This last paper summarizes the previous research conducted by Trueswell.)

34. Allen Kent et al, Use of Library Materials: The University of Pittsburgh Study (New York: Marcel Dekker, 1979).

35. Slote, "Analysis and Review of the Literature of Weeding."

36. Trueswell, "Growing Libraries."

37. Ibid., 93.

38. Ibid., 84-85.

39. Herman H. Fussler and Julian L. Simon, Patterns in the Use of Books in Large Research Libraries (Chicago: Univ. of Chicago Pr., 1969): 144-47.

40. Ibid., 128 .

41. Charles F. Gosnell, "Obsolescence of Books in College Libraries," College E Research Libraries 4 (Mar. 1944): 115-25; Collection Management 2 (summer 1978): 167-82.

42. - Collection Management, 176.

43. Ibid., 177.

44. Ibid., 181.

45. Line and Sandison, "'Obsolescence' and Changes in Literature over Time," 302.

46. Aridaman K. Jain, "A Statistical Study of Book Use Supplemented with a Bibliography of Library Use Studies" (Ph.D. diss., Purdue University, 1967).

47. Ibid., 125.

48. George V. Hodowanec, "Literature Obsolescence, Dispersion, and Collection Development," College $\mathcal{E}$ Research Libraries 44 (Nov. 1983): 421-43.

49. Ibid., 425.

50. "Standards for Community, Junior, and Technical College Learning Resources Programs: The New Standards, Approved by ACRL and AECT," College E Research Libraries News 51 (Sept. 1990): 757-76.

51. Hodowanec, "Literature Obsolescence, Dispersion, and Collection Development," 425.

52. Line and Sandison, "'Obsolescence' and Changes in Literature over Time," 284.

53. Trueswell, "Growing Libraries," 72-104.

54. Daniel Gore, ed. Farewell to Alexandria: Solutions to Space, Growth, and Performance Problems of Libraries (Westport, Conn.: Greenwood Pr., 1975): 164-80. 